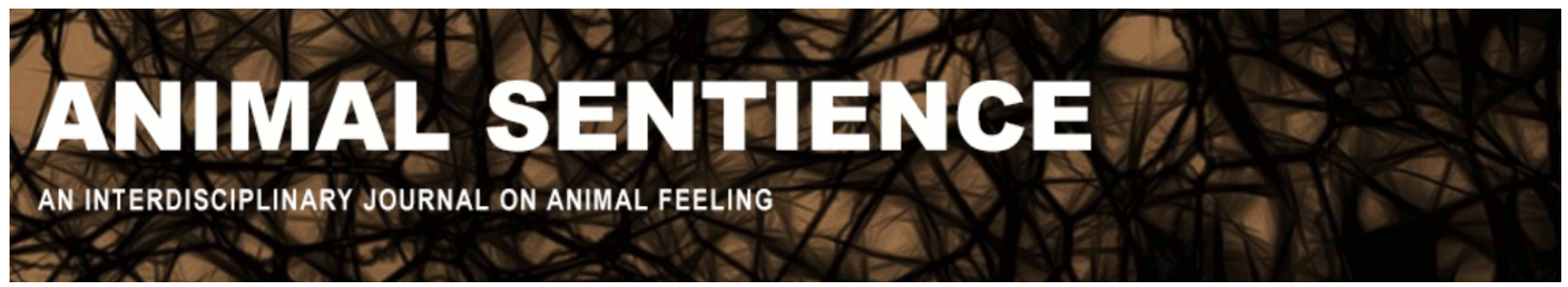

Rowlands, Mark (2016) Consciousness and the unity of mind. Animal Sentience 10(14)

DOI: $10.51291 / 2377-7478.1167$

Date of submission: 2016-09-28

Date of acceptance: 2016-10-10

(c)

This article has appeared in the journal Animal

Sentience, a peer-reviewed journal on animal

cognition and feeling. It has been made open access,

free for all, by WellBeing International and deposited

in the WBI Studies Repository. For more information,

please contact

wbisr-info@wellbeingintl.org.

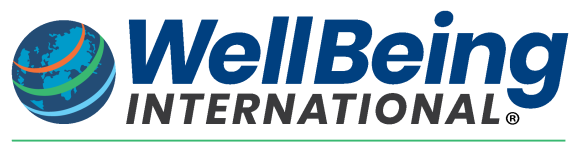

SOLUTIONS FOR PEOPLE, ANIMALS AND ENVIRONMENT 


\title{
Consciousness and the unity of mind
}

\author{
Response to Commentary on Rowlands on Animal Personhood
}

\author{
Mark Rowlands \\ Department of Philosophy, University of Miami
}

\begin{abstract}
Several types of objection have been raised against the arguments I presented in my target article, "Are animals persons?" Among the objections are the following: (1) the claim that animals are persons is of little significance, (2) my use of the Lockean conception of the person is questionable, (3) whether a creature qualifies as a person is a matter of social construction rather than objective fact, (4) reflective consciousness is more important than I realize, (5) my reliance on implicit self-awareness in the account of personhood is illadvised, (6) my account entails that too many creatures qualify as persons, and (7) types of objection that resist categorization (but I shall argue are sundry misunderstandings). I respond to these objections.
\end{abstract}

\footnotetext{
Mark Rowlands, Professor of Philosophy at University of Miami, studies philosophy of mind, ethics and moral psychology. He has written 18 books, including Animal Rights (Macmillan, 1998), The Environmental Crisis (Macmillan, 2000), Animals Like Us (Verso, 2002), The Philosopher and the Wolf (Granta, 2008), and Can Animals Be Moral? (Oxford, 2012). http://www.as.miami.edu/phi/people/
}

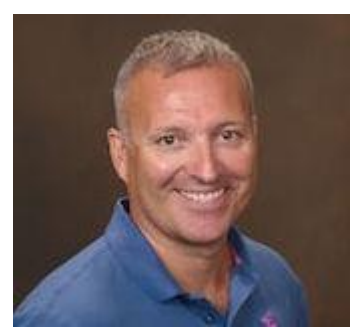

I am enormously grateful to all those who took the time to respond to my target article Are animals persons? (Rowlands 2016a). These responses of mine are offered in this spirit of gratitude. While I find myself in agreement with many of the commentators, various areas of disagreement undoubtedly exist, and I am delighted to have this opportunity to clarify or reinforce my position. I have organized my comments by way of certain prevailing themes that emerged in the comments rather than on a commentator-by-commentator basis.

To begin, let me recap some of the central ideas of the target article. First, there are three common assumptions - one of which I accept, the other two I challenge.

1. A person, I accept for the sake of argument, is a unified mental life. This assumption is contestable. On the one hand, there are those who think a person is not an essentially psychological entity at all, but a physical entity. Such a person, however, is far less likely to be hostile to the idea that animals are persons. On the other hand, there are those (e.g., Parfit 1984) who think that having a unified mental life is not sufficient for being a person. The latter position is beyond the scope of my target article; I merely note this and move on. The core of my article concerns self-awareness rather than personhood as such. 
2. It is common to assume that unity is something added to a mental life. On the one hand, there is a mental life - a succession of thoughts, feelings, emotions and the like. On the other, there is the question of whether this succession of thoughts, feelings and emotions forms a unified whole. There could be a mental life that was merely a jumble of disassociated mental states. For a mental life to be unified, something extra must be added, over and above the mere presence of mental states and processes.

3. The additional element, it is equally common to assume, is provided by reflective selfawareness. When someone is reflectively self-aware, one has a mental state that is either about (1) oneself, (2) one's bodily state, or (3) one's mental state. Either oneself or one's bodily state or one's mental state is the intentional object of one's mental state. For example, if I think I'm getting old, that my knees are not what they used to be, or that I am in pain, I am reflectively self-aware. Crucial to reflective self-awareness is the existence of an intentional state that is directed towards the person, or some or other facet of the person, who has it. When Locke says that a person is able to consider itself as itself, the same thinking thing from one time to another, it is tempting (and common) to understand Locke's claim as one of reflective self-awareness: a person is able to think of itself as itself, etc.

Against assumptions (2) and (3), I argue the following:

4. Assumption 2 is false. The unity of a mental life is built into having experiences: if something has experiences at all, then its mental life is automatically unified. The crucial qualification here is that I understand experiences as intentional states - states that are about or directed towards things. I never merely see, I always see something, etc. The way I use the notion of an experience, the expression "intentional experience" would be an oxymoron (and the expression "non-intentional experience" a contradiction). Once you have intentional states, I argue, you have a unified mental life. I am, for the record, a rabid intentionalist about the mental. Anything that qualifies as mental, I think, must be intentional. Mental states that, to some, do not seem to be intentional - sensations, feelings, etc. - should, in fact, be understood in intentional terms. I recognize that many do not share this view, and I do not presuppose it in developing the arguments of the target article. To those who do not share this view, I should simply note that my argument is that once you have intentional states, you have a unified mental life. If there are states that are mental but non-intentional, then my argument does not apply to them. A creature whose only mental states were non-intentional sensations would not have a unified mental life. Or, at least, nothing I have argued suggests that they would.

5. The reason the presence of intentional states guarantees the unity of a mental life stems from the nature of intentional directedness. To be intentionally directed towards the world is to be related to something as something. If someone holds up an item in front of me, I don't just see it, I see it as something: as a book, as a bottle, etc. To have an experience is to experience something as something (See Rowlands 2010, Chapter 7, for defense). Sartre, whose influence on my paper is quite clear, characterized conscious experience as what he called a "revealing intuition." In having an experience, the world is revealed or disclosed to me as being a certain way. There is, of course, no commitment to any particular "as." That 
varies from case to case. But some or other "as" is involved in anything that counts as intentional directedness.

6. If claim 4 is correct, then the idea that reflective self-awareness is required for the unity of a mental life (claim 3 above) is false. Moreover, I argued that there are additional independent reasons for thinking that reflective self-awareness cannot be the basis of the unity of a mental life. Trying to capture the unity of a mental life in terms of reflective selfawareness leads to a regress: the appeal to an additional act of reflective consciousness merely raises the question of whether this act is unified with the mental life it is supposed to unify.

With this recap of the main points in mind, let me turn to the commentaries. They can be grouped into several different, although in some cases partially overlapping, categories.

\section{Who Cares?}

Broude questions whether we should care about the question of whether animals are persons:

"Perhaps we should worry less about definitions of personhood and more about whether and why (all) animals deserve certain kinds of treatment by human animals."

I get this a lot. Ironically, elsewhere I have written quite a lot about our moral obligations to animals. The crucial point, however, is that the sort of treatment we owe an animal is not independent of the sort of thing it is and the features it has. Thus, something that is sentient merits very different treatment from something that is not. Similarly, if a creature's mental life is unified, it can be harmed in ways that something without a unified mental life cannot. Death is the most obvious of these ways, but there are others. Boredom, for example, may be suffered by a creature that has a unified mental life but not by one that does not. BenzSchwarzburg is very clear on this point:

"What special capacities, and above all, vulnerabilities does pre-reflective selfawareness give animals? What do we owe them because of this? And how strongly do we owe it them?"

As she points out, while a right not to be tortured can be grounded in mere possession of a mental life, whether unified or not, certain other rights - life and liberty - require more than this. The end or confinement of a unified mental life is a very different thing than the end or confinement of a series of dissociated mental states.

One further point should be noted. When I describe the category of personhood as metaphysical, rather than moral or legal, I certainly wouldn't want to suggest that this conception has no moral implications. Monsó is absolutely right on this matter. My characterization is not a moral one in the sense that it does not define a person in moral terms: it does not, for example, define a person as a being worthy of a certain kind of moral 
consideration. But this is perfectly compatible with the category of a person being morally salient. Compare: sentience is not a moral concept - but it certainly has moral implications.

\section{Why the Lockean Conception of the Person?}

There is a group of commentaries that concern my choice of the Lockean conception of the person. Cheng writes:

"It is unclear why Rowlands would want to start with this definition ... Locke's definition is primarily designed to deal with personal identity. That is why it emphasizes the temporal dimension ('in different times'). But what is at issue is personhood."

Broude goes further:

"We could conjecture that Rowlands is redefining person so that every animal gets to be one."

I'll deal with Broude's claim first. I am puzzled by Broude's "conjecture" that I have redefined the notion of a person, since the conception of a person I use is Locke's, not mine. Perhaps the charge is that I employ the notion of pre-reflective conscious only to ensure that animals turn out to be persons? Obviously, I am not hostile to the conclusion that animals can be persons, but the charge that I am somehow feeding this conclusion into the argument does seem to be baseless. My argument looks like this: (1) the relevance of metacognition to personhood is that it is thought to confer unity on a mental life, and (2) this unity can be conferred by pre-reflective awareness, and (3) it cannot be conferred by reflective awareness. There is no circularity here.

Turning to Cheng, it is true that Locke, in his Essay Concerning Human Understanding, raises the question of what the word "person" stands for in connection with the issue of personal identity. But the definition is logically independent of this concern, and can be assessed independently of the role it plays in Locke's account of personal identity. I use his definition as a well-known exemplar of the view I want to attack: that being a person requires self-awareness, and self-awareness requires reflective consciousness.

To see why this is important, consider Benz-Schwarzburg's list of personconferring attributes, which she takes from White (2007):

"These features include (1) being alive, (2) being aware, (3) feeling positive and negative sensations, (4) having emotions, (5) having a sense of self, (6) controlling one's own behaviour, (7) recognizing other persons and treating them appropriately, and (8) having a variety of sophisticated cognitive abilities, such as analytical thinking, learning, or complex problem solving."

Given what we now know and accept about animals, the following claims are very likely to be true. Many animals meet the following conditions. They are (1) alive. They are (2) aware 
of their environment. They have (3) both positive and negative sensations. They have (4) emotions. They can (6) control their own behavior. (If you doubt this, you should see Hugo, my German shepherd, execute what's called the down in motion). They can (7) recognize other persons and treat them appropriately. They have (8) a variety of sophisticated cognitive abilities, and some of them are capable of both causal and (the prognostications of some philosophers aside) logical reasoning. Not so long ago, many of these claims on behalf of animals would have been roundly rejected - indeed ridiculed. But times have changed. So, if we ignore White's condition (5) - sense of self - then the case for animal personhood seems very strong indeed. Condition (5) is going to be the sticking point - the last bridgehead for those who want to deny that animals can be persons. This bridgehead will be made particularly secure if they can show that (a) sense of self requires meta-cognitive abilities, and (b) animals don't have these. Put in these terms, my argument is that having a sense of self does not require meta-cognition, and so the issue of whether animals are capable of this is irrelevant. That, in a rather large nutshell, is why I chose to work with Locke's definition.

\section{Persons: Objective or Socially Constructed?}

Irvine makes some very interesting points on a variety of topics. I find myself in agreement with much of what she says. There is one issue, however, that might provide a source of disagreement: the sort of disagreement one often finds between sociologists and philosophers. It concerns her idea of the "collaborative manufacture" of the person. Whether or not an individual qualifies as a person is, as I understand it, an objective matter. It is the sort of thing about which one might be mistaken. Indeed, we are routinely mistaken about animals, many of whom are persons while many or most humans think they are not. This seems to be quite different from the kind of view expressed in passages such as this. Irvine writes:

"Owners also saw their dogs as individuals and could easily describe what a particular dog 'was like.' They saw their dogs as having a range of emotions and demonstrating sensitivity to emotions in others. In addition, they incorporated their dogs into household practices through mealtimes and opportunities for play and exercise, and into family rituals such as birthdays and holidays....These analyses offer a clear sense of the social construction of personhood among animals through everyday interaction."

I do not think of persons as socially constructed entities. Humans and other animals are persons independently of whether there are social practices that construe or "construct" them as such.

\section{Reflective Consciousness Is Required for Personhood}

Another group of commentaries was concerned in one way or another with rehabilitating reflective consciousness. Broude writes: "Those who promote the orthodox view of what it takes to have unity of mental life think that there is a difference between implicit and explicit self-reflectiveness that is not trivial." But, of course, I do not claim the difference between these two things is trivial. Far from it, I argue that reflective (or as Broude prefers, 
"explicit") self-awareness cannot ground the unity of a mental life, whereas pre-reflective ("implicit," as Broude uses this term) self-awareness can (or is in a better position to) do so. This means that the distinction is far from trivial. I cannot find an argument in Broude's commentary that shows that reflective self-awareness can ground the unity of a mental life.

In pressing the credentials of reflective self-awareness, Woodruff invokes Baker's (2013) distinction between rudimentary and robust conceptions of personhood: "A rudimentary first-person perspective exists when a subject has 'the capacity to interact, consciously and intentionally, with the environment from a particular location' (p. 170)....A subject shows a robust first-person perspective, and is considered to have personhood when there is 'the capacity to think of oneself, conceived in the first person, as the object of one's thought'" (p. xix). This is, in essence, the Lockean view as it is traditionally understood, although Baker is willing to allow a diminished - rudimentary - form of personhood to those who do not satisfy the Lockean requirements but meet others. I have argued that "the capacity to think of oneself" is not required for personhood in either form, because this capacity cannot do the job it is thought to do: confer unity on a mental life. But one cannot show, logically speaking, that my arguments are mistaken merely by reiterating the position I attack. That would commit the logical fallacy of begging the question. In invoking Baker, Woodruff assumes my view is incorrect, but he does not show it. He begs the question.

Woodruff later reiterates the same sort of point: "I also think it is an error to remove intentionality and higher-order thought processes from the criteria for what constitutes a person." I'm puzzled by the idea that I have somehow removed intentionality from the picture. On the contrary, intentionality is absolutely central to the entire picture: prereflective self-awareness is something that attaches only to intentional states. Without intentionality there is no pre-reflective awareness and without pre-reflective awareness there are no persons. Intentionality is at the heart of my view of the mind and has been for as long as I can remember (see Rowlands 2010 for a recent example).

Perhaps Woodruff means higher-order intentionality: thoughts about mental states? Higher-order thoughts are a different matter - I do deny these are required for personhood. Cheng also highlights the issue of higher-order thoughts:

\section{"Rowlands does mention higher-order theories, but without substantive discussion."}

See Rowlands 2001a, 2001b, 2009, and 2012 for substantive discussion. However, Cheng thinks I am picking a fight I needn't pick (and, admittedly, it wouldn't be the first time).

"'My being in pain is not independent of my awareness of being in pain.' This is a strong claim in philosophy of mind; for example, it is a denial of every version of higher-order theory of consciousness."

As a matter of fact, I do want to deny every version of higher-order theories of consciousness. I think higher-order theories are not just wrong, but disastrously so. The fundamental mistake they make is to confuse consciousness of and consciousness with. A 
mental state is not conscious because I am conscious of it. It is conscious because I am conscious with it. For example, the vast majority of the beliefs I have are, at any given time, unconscious. A belief becomes conscious not because I start thinking about it or because I have some sort of higher-order introspective experience of it, but because it makes me conscious of what it is about. My belief that Ouagadougou is the capital of Burkina Faso becomes conscious when it makes me aware that Ouagadougou is the capital of Burkina Faso. Or, consider seeing. I consciously see something when my visual experience makes me aware of an object, not because I am thinking about my visual experience or (somehow!) experiencing it. How do they do that? Good question - but solving the hard problem of consciousness is well beyond the remit of this paper. Suffice to say, it's not by having a highorder state about them (see Rowlands 2001a, 2001b, and 2012 for explanation why).

Higher-order theories, or close cousins thereof, are the single biggest source of the attempted disenfranchisement of animals of not just personhood but - among other things - consciousness (Carruthers 1989), beliefs (Davidson 1982), visual experience (McDowell 1993) and certain sorts of agency (Korsgaard 2004). I suspect the battle lines are being drawn up precisely here. Meta-cognition, and the higher-order more generally, will be infused into capacities that really don't require them, and will be used to keep animals out of the mental and moral club. Maybe Cheng is right, and I don't need to get into this fight for the purposes of the present paper. I could have just said: "My being in pain is not independent of my pre-reflective awareness of being in pain." But the fight is coming anyway.

\section{Implicitness}

Several commentators either questioned my use of the term "implicit" or used it in ways I wouldn't endorse. Woodruff requests a clarification on the notion of "implicit" used in the target article. The notion of "implicit" is not univocal. In psychology it means more than one thing, and the same is true in philosophy. I used what is sometimes called the formationdispositional account of implicitness, where the notion of implicit is understood in terms of the disposition to have explicit states. This formation-dispositional account is evident in the criterion of identity of pre-reflective awareness developed in section 8 ("Pre-reflective awareness: a criterion of identity"). The purpose of this section is to specify the conditions under which a subject is pre-reflectively aware of a given mental state. Roughly, an individual is pre-reflectively aware of a mental state when it has a mental state (that does not possess I-content), and having this mental state, in an appropriate context (made up of the requisite meta-cognitive abilities), would dispose the individual to having an explicit state with I-content.

Woodruff, on the assumption that implicit self-awareness is unconscious, claims:

"[I]t is difficult to see how such a unity could contribute to the sense of 'being the same thinking thing."'

Two points should be noted here. First, I do not claim that pre-reflective awareness is unconscious. There is nothing unconscious about pre-reflective self-awareness. When I am 
pre-reflectively aware of my mental states, I am aware of them - but pre-reflectively rather than reflectively. Secondly, and more importantly, I don't think it is hard at all to understand how this non-explicit (let us call it) self-awareness could give rise to a sense of unity. To see why this is so, consider, first, the sense of unity of something that is not the self. Suppose someone holds up a bottle in front of me. I see it as a bottle. But it is also true that light is being reflected to my eye from only part of the bottle. Why does it seem to me as if I am seeing bottle - as opposed to a bottle façade? The answer provided by the phenomenological tradition (and more recently taken up by the predictive processing camp) is that I have generated various expectations about how the appearances will change in the event of certain things happening (the bottle being rotated, the bottle moving relative to me, my moving relative to the bottle, etc.). These expectations are not explicit. I do not have to be thinking any of them. But I nonetheless have them, and it is because I have them that I see the object in front of me as a bottle rather than, say, a bottle façade (see Noë 2004). The idea that implicit mental states can ground a sense of unity is not unfamiliar. My argument is an application of this idea to pre-reflective awareness of the self.

\section{Too Many Persons}

King identifies an issue that - I have to admit, when it first occurred to me, early in the development of this idea - did cause me a sleepless night or two:

"The low bar of mere pre-reflective awareness would allow attribution of personhood to an absurdly large number of species, primate and non-primate, who would fail Hare's test but still pass a less restrictive test for pre-reflective awareness."

According to the view I defend, the category of the person is co-extensive with the category of things that have (oxymoron alert - "intentional") experience. Any creature that has experience is a person. Experience is, however, not the same thing as mere sensation or feeling. These, at least as commonly understood, need not be intentional. If a creature is the subject of merely non-intentional sensations or feelings, then nothing I have said entails that it is a person. The category of the person does become larger - there is no question about that. But it is not, in my view, "absurdly" large.

I take no stand, in the target article at least, on the subject of which animals have experiences and so qualify as persons. If I did take a stand, the following comments of King would be apposite:

"Instead, between-species comparisons must be based on observational and experimental procedures to demonstrate the extent to which human mental attributes are shared with other species. This would allow a more informed view about the appropriateness of personhood in nonhumans."

Indeed, any attempt to establish which animals qualify as persons, and which do not, would have to rely on such procedures. But since that is not my goal in the paper, I do not. King's comments might be read, perhaps uncharitably, as claiming that I am uninformed. But the idea of being informed is, of course, elliptical - being informed is always being informed 
about or regarding something. I provided (at least this was the goal) an informed discussion of the varieties of self-awareness as these pertain to the idea of a person. I did not say things such as species $\mathrm{X}$ is in the personhood club, species $\mathrm{Y}$ is not.

On the subject of what gets counted as persons, the comments of Цürgens suggest that insects might be capable of pre-reflective self-awareness.

"Spiders of the genus Portia exhibit a highly flexible stalking behavior involving careful spatial navigation relative to a prey which may partly be out of sight. This indicates Portiae's capacity for complex planning towards an implicit goal and for representing the position of its own body in three-dimensional space. Such a representation of self, though rudimentary, may count as an example of an implicit self in Rowlands's sense."

It may do. I take no stand on this. It all depends on whether you think spiders are (a) sentient, and (b) whether their sentience takes the form of experience rather than sensation (see Klein \& Barron's 2016 target article for a discussion of consciousness in insects). Assessing the personhood credentials of any particular species is not the goal of my target article.

Jürgens also draws attention to what she seems to regard as a questionable assumption:

"Rowlands's analysis seems to be based on phenomenological introspection and the assumption that pre-reflective awareness is essentially the same for all sentient beings."

Yes, I do make that assumption. This is because pre-relective awareness is not a feature of experience but a precondition of it. Pace Jürgens, pre-reflective awareness is not revealed to phenomenological introspection - whatever that is (don't get me started, but see Rowlands $2016 \mathrm{~b}$ if you want to see me get started). There is nothing that it is like to be pre-reflectively aware of an experience over and above what it is like to have the experience itself. So, I do not assume that pre-reflective self-awareness feels the same way for all creatures. Prereflective self-awareness does not feel like anything at all.

I'd like to mention one final matter on the subject of the scope of the category of the person - not a response to a specific comment, but a more general observation. Many assume that it is common sense that only humans can be persons. My claim to the contrary is, accordingly, a violation of this sense. In fact, common sense is conflicted on this issue. Common sense often is. In fictional contexts, we are quite happy to talk of persons that are not humans. Yoda was a person: not human, of course, but a person nonetheless. So too was Jabba the Hutt, Jar Jar Binks, etc. It is easy to prematurely dismiss these cases: How can these sorts of science-fictional cases tell us anything at all? How can reflections on entities that don't even exist show us anything worthwhile? Actually, they can. One person's fiction is another's counterfactual. And counterfactuals can tell us plenty. 
Suppose you don't know the meaning of a word. You have heard the word for the first time, and you are trying to work out what it means. You can find this out by asking questions of a conditional form. A conditional statement looks like this: if ... then .... What follows the "if" is known as the antecedent. And what follows the "then" is known as the consequent. So, you have heard the word "bachelor" for the first time, and are trying to ascertain its meaning. You can do this by finding out the truth or falsity of certain crucial conditionals. If something is a female can it be a bachelor? No, you are told - and this gives you vital information about what the words means. If something is married, can it be a bachelor. No, you are told, and this gives you further vital information. The point is that conditionals of this sort can tell you what a word means. But conditionals divide into two sorts. Sometimes the antecedent - the claim that follows "if" - is true. Sometimes it is not. When it is not, the conditional is what's called a counterfactual. But for the purposes of finding out what a word means, it doesn't matter one bit whether the conditional is or is not a counterfactual. Yoda doesn't exist. We all know that. But we can still ask the following counterfactual: if Yoda did exist, would he be a person? If you decide that he would, then this tells you something very important about what you must mean by the word "person." Such is the power of the fictional, the counterfactual: They can tell us something important about the way we think of persons. They reveal to us our concept of a person. They show us that if someone like Yoda were to exist, then they would be a person - even though they are not human. Therefore, the word "person" does not simply mean the same as "human." People think it is common sense that only humans are persons. But, on the contrary, common sense, augmented with a little imagination, effortlessly distinguishes humans and persons.

These imaginative counterfactuals that we know as science fiction are merely expressions of Locke's distinction between a human and a person. The category of human being is a biological one - a matter of having a certain genome. The category of person, on the other hand, is, for Locke, a psychological one: a person is something that has the right sort of mental life - thought, intelligence, reason, reflection, and the ability to "consider" oneself the same thinking thing.

We habitually confuse the category of the human with that of the person for the simple reason that most humans are persons. Most but not all: a human who has suffered severe brain damage, for example, resulting in the complete and irreversible loss of all mental functioning is a human but not, if Locke is right, a person. And imagined alien life forms with complex psychological lives show that it is possible for there to be persons that are not humans. If it is even possible for there to be persons who are not humans, this shows that "person" doesn't simply mean "human." That's common sense.

\section{Sundry Misunderstandings/Qualifications}

King makes a point that is, I think broadly correct, but also irrelevant to the target article:

"The problem with this argument is that personhood has an open-ended list of defining attributes and can, at best only be partially applied to nonhuman species. Therefore, a 
dichotomous distinction cannot be made between qualifying and non-qualifying species."

Yes: the perils of a craving for generality that afflicts philosophers and scientists in equal measure. You spend twenty years investigating, say - off the top of my head - whether cognition requires representation, only to discover that the idea of representation breaks down into at least 27 different varieties and your guiding question, unfortunately, doesn't make a lot of sense (Rowlands 2015). The antidote to this craving for generality (as Wittgenstein called it) - and this is why King's point is irrelevant to the concerns of this paper - is to always deal in specifics. So, I dealt with a quite specific conception of a person: a person is a subject of a unified mental life. My target is, then, anyone who thinks that animals cannot be persons because the required unity of a mental life can only come from reflective self-awareness. The conception of the person is specific, and the resulting target is specific, and that is why King's objection does not apply.

\section{Woodruff writes:}

"The core of [Rowlands's] argument is that the perception of the affordances of an object such as a chair creates an awareness of self in the observer without the need for the observer to perceive (be aware of) its own body. This awareness does not require higher-order thought processes."

This is inaccurate in at least two ways. First, the observer is aware of its body - but prereflectively rather than reflectively. Second, affordances do not lie at the core of my argument, although they provide good examples of the argument at work. But the first example I used (in Section 6: "Seeing as") was seeing something as a book (rather than, for example, a book façade), and this is not an affordance. Affordances are not, therefore, at the core of the argument. The idea of seeing-as is what is crucial, not the idea that things are seen specifically as affordances.

\section{Broude writes:}

"My dog experiences a bone as a bone. And personhood extends into the animal realm whenever there is experiencing as. Does my dog experience a bone as a bone, though? It depends upon what the meaning of 'as' is. And to whom $X$ is experienced as $X$. When I perceive a bone as a bone, I am exploiting my prior abilities to form and recognize concepts and categories. I can explicitly list features of items belonging to the category of book, chair, and bone, for instance. My dog cannot, I think."

My claim, however, is not that a dog experiences a bone as a bone. (This was cited merely as a candidate possibility, nothing more. I suspect affordances would be better candidates. But, I should reiterate, this is an empirical issue.) My claim is that if it has experience at all, then the dog will experience the bone as something. What, precisely, this is cannot be decided from the armchair, but will require extensive investigation of the representational capacities of dogs. But if dogs have experience at all, as opposed to merely sensation, then 
they will experience the bone as something (see Rowlands 2012, Chapter 2, for further discussion).

\section{King writes:}

“A fundamental problem with Rowlands's argument is illustrated by his example of a chimpanzee who avoids a desirable food when a more dominant chimpanzee is nearby. Was this a case of higher order intentionality where the submissive chimpanzee knows what the dominant chimpanzee is thinking or is it simply 'behavior-reading?' Rowlands suggests that even if it is merely behavior-reading, the chimpanzee meets Locke's test because it passes the test for pre-reflective awareness."

That was not my point in discussing Povinelli's response (Povinelli and Vonk 2003, Penn and Povinelli 2007) to the Hare, Call and Tomasello (2001) experiment. My point in discussing Povinelli's skeptical argument was to show that the existence of higher-order intentional states in animals is controversial - thus motivating the attempt to understand self-awareness in other terms. It was not to argue that the chimp was pre-reflectively selfaware.

\section{Animals and the History of Philosophy}

Benz-Schwarzburg suggests the Lockean conception of the person is both egocentric and logocentric. I'm not quite sure what logocentric means, but I take it that it has to do with being "solipsistic" and "rationalistic." One of the advantages of the idea of pre-reflective consciousness, she suggests, is that it allows us to think of the self in more relational terms, spread out into the body and its social relations. This point strikes me as correct. If I understand Brakel correctly, it is also consonant with her emphasis on agency.

Benvenuti bemoans, quite justifiably in my view, the track record of philosophers' pronouncements on animals. She writes:

"It is worth noting the persistence of certain philosophical notions even when contradicted by the evidence. I have described three: the Aristotelian notion that humans are distinct from and superior to other animals because of our capacity for abstract thought; the Cartesian notion that affective 'passions' interfere with thought, rather than informing it; and the Lockean notion that only humans have the rational self-awareness required for personhood. Philosophical hostility to the idea of animal personhood may in fact derive from human psychological motives to consider ourselves distinct from and superior to other animals - to be authorized to use other animals de facto, and to avoid painful feelings of empathy for their suffering."

I agree - but in (marginal and muted) defense of my discipline I should probably note that scientists have, until recently, been just as bad. As an antidote to these kinds of tendencies, I suggest two methodological rules of thumb. First, whenever there is a capacity that animals seem to have, and also a philosophical account that entails they cannot have it, the latter should be treated with considerable suspicion. The philosophical account may ultimately 
turn out to be correct, but the initial, operative, assumption should be that it is not. Much work will have to be done if the philosophical account is to prove ultimately acceptable. Second, since controversial philosophical doctrines have a habit of evolving into common sense, I advance a second, methodological rule: when empirical evidence suggests that animals have a capacity that common sense thinks they cannot, we are obliged to take this evidence seriously, to examine why common sense arrived at this conclusion, and whether it was right to do so. We are all philosophers, as Wittgenstein once suggested, and therefore prone to their habitual ailments.

Finally, I strongly agree with Rollin's flawless historical analysis. The position I defend has a clear Kantian inspiration if we divest Kant of his assumption that only humans can have pre-reflective self-awareness (transcendental apperception, as Kant called it). I sense a growing realization among those working on the question of self-awareness in animals that the kind of awareness tested for in the mirror test is not the only kind of selfawareness (see Broom's 2016 to the commentaries on his target article in this journal for similar sentiments). Given Kant's official denigration of animals, the historical irony is delicious or monstrous - depending on your perspective. What was needed all along was more Kant!

\section{References}

Baker, L. R. (2013) Naturalism and the first-person perspective. (Oxford: Oxford University Press)

Benvenuti, A. (2016) Evolutionary continuity of personhood. Animal Sentience 2016.141

Benz-Schwarzburg, J. (2016) From thinking selves to social selves. Animal Sentience 2016.130

Benz-Schwarzburg, J. (2016) What do we owe animals as persons? Animal Sentience 2016.129

Bernecker, S. (2010) Memory: A Philosophical Study. (New York: Oxford University Press)

Brakel, L. A. W. (2016) Animals are agents. Animal Sentience 2016.103

Broom, D. M. (2016) Sentience and animal welfare: New thoughts and controversies. Animal Sentience 2016.057

Broude, G. J. (2016)Who is a person? Whoever you want it to be. Animal Sentience 2016.112

Carruthers, P. (1989) Brute experience. Journal of Philosophy, 86, 258-269

Cheng, T. (2016) Why animals are persons. Animal Sentience 2016.105 
Davidson, D. (1982) Rational animals. Dialectica, 36, 317-328

Hare, B., Call, J., and Tomasello, M. (2001) Do chimpanzees know what conspecifics know? Animal Behavior, 61, 139-151

Irvine, L. (2016) The person and the self as social accomplishment. Animal Sentience 2016.136

Jürgens, U. M. (2016) Universal modes of awareness? A “pre-reflective” premise. Animal Sentience 2016.116

King, J. E. (2016) Animal personhood is an evolutionary issue. Animal Sentience 2016.139

Klein, C., and Barron, A. B. (2016) Insects have the capacity for subjective experience. Animal Sentience 2016.100

Korsgaard, C. (2004) Fellow creatures: Kantian ethics and our duties to animals. Tanner Lectures on Human Values, 24, 77-110

McDowell, J. (1993) Mind and World. (Cambridge, MA: Harvard University Press)

Monsó, S. (2016) The moral dimension of pre-reflective self-awareness. Animal Sentience 2016.121

Noë, A. (2004) Action in Perception. (Cambridge, MA: MIT Press)

Parfit, D. (1984) Reasons and Persons. (Oxford: Oxford University Press)

Penn, D., and Povinellli, D. (2007) On the lack of evidence that non-human animals possess anything remotely resembling a theory of mind. Philosophical Transactions of the Royal Society $B, 362,731-744$

Povinelli, D., and Vonk, J. (2003) Chimpanzee minds: suspiciously human? Trends in Cognitive Sciences, 4(4), 157-160

Rollin, B. E. (2016) Unity of consciousness in animals. Animal Sentience 2016.125

Rowlands, M. (2001a) Consciousness and higher-order thoughts. Mind and Language, 16(3), 290-310

Rowlands, M. (2001b) The Nature of Consciousness. (Cambridge: Cambridge University Press)

Rowlands, M. (2009) Animal Rights: Moral Theory and Practice. (Basingstoke: Macmillan) 
Rowlands, M. (2010) The New Science of the Mind: From Extended Mind to Embodied Phenomenology. (Cambridge, MA: MIT Press)

Rowlands, M. (2012) Can Animals Be Moral? (New York: Oxford University Press)

Rowlands, M. (2015) Arguing about representation. Synthese, 1-18. doi:10.1007/s11229014-0646-4

Rowlands, M. (2016a) Are animals persons? Animal Sentience 2016.101

Rowlands, M. (2016b) Memory and the Self. (New York: Oxford University Press)

White, T. (2007). In Defense of Dolphins: The New Moral Frontier. (Oxford: Blackwell)

Woodruff, M. L. (2016) Implicit mental processes are an improbable basis for personhood. Animal Sentience 2016.102 